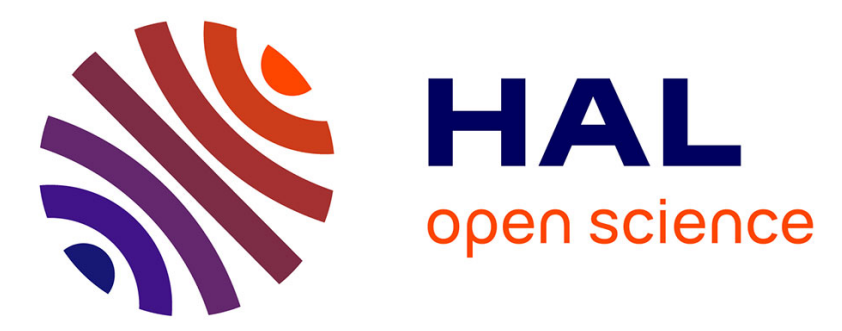

\title{
Prognostic factors for skeletal complications from metastatic bone disease in breast cancer
}

Janet E. Brown, Richard J. Cook, Allan Lipton, Luis Costa, Robert E. Coleman

\section{- To cite this version:}

Janet E. Brown, Richard J. Cook, Allan Lipton, Luis Costa, Robert E. Coleman. Prognostic factors for skeletal complications from metastatic bone disease in breast cancer. Breast Cancer Research and Treatment, 2010, 123 (3), pp.767-779. 10.1007/s10549-010-0981-1 . hal-00550174

\section{HAL Id: hal-00550174 https://hal.science/hal-00550174}

Submitted on 24 Dec 2010

HAL is a multi-disciplinary open access archive for the deposit and dissemination of scientific research documents, whether they are published or not. The documents may come from teaching and research institutions in France or abroad, or from public or private research centers.
L'archive ouverte pluridisciplinaire HAL, est destinée au dépôt et à la diffusion de documents scientifiques de niveau recherche, publiés ou non, émanant des établissements d'enseignement et de recherche français ou étrangers, des laboratoires publics ou privés. 


\section{Prognostic Factors for Skeletal Complications From Metastatic Bone Disease in Breast Cancer}

Janet E. Brown, ${ }^{1,2}$ Richard J. Cook, ${ }^{3}$ Allan Lipton, ${ }^{4}$ Luis Costa, ${ }^{5}$ Robert E. Coleman ${ }^{2}$

1'University of Leeds, Cancer Research UK Clinical Centre, Leeds, UK; ' 2 University of Sheffield, Cancer Research Centre, Weston Park Hospital, Sheffield, UK; ${ }^{3}$ University of Waterloo, Waterloo, Ontario, Canada; ${ }^{4}$ Milton S. Hershey Medical Center, Pennsylvania State University, Hershey, Pennsylvania, USA; ${ }^{5}$ Hospital de Santa Maria, Lisbon, Portugal

Running title: Prognostic factors for breast cancer skeletal complications

\section{Address reprint requests to}

Janet E. Brown, MD

Cancer Research UK Clinical Centre, Leeds

JIF Building

St. James' University Hospital

Beckett Street

Leeds LS9 7TF United Kingdom

Phone: 44-113-2064184

Facsimile: 44-113-2460136

E-mail: j.e.brown@leeds.ac.uk

Text word count (limit 3500): 3500 


\section{Conflicts of Interest}

- Janet Brown has received speakers bureau honoraria from Novartis and Amgen and has served as a consultant and/or on advisory boards for Novartis, Amgen, Roche, and Bristol-Myers Squibb.

- Richard Cook has served as a consultant and/or on advisory boards for Novartis and Abbott.

- Allan Lipton has received commercial research grants from Novartis, Monogram Biosciences, and Oncogene Science; has received speakers bureau honoraria from Novartis, Amgen, and Genentech; has served as a consultant and/or on advisory boards for Novartis, Amgen, Galapagos, Acceleron Pharm, and has given expert testimony for Novartis.

- Luis Costa has received speakers bureau honoraria from Novartis and has served as a consultant and/or on advisory boards for Novartis and Amgen.

- Robert Coleman has received other commercial support from Novartis; speakers bureau honoraria from Novartis and Amgen; has served as a consultant and/or on advisory boards for Novartis, Amgen, Pfizer, and Roche; and has previously given expert testimony on the behalf of Novartis. 


\section{ABSTRACT}

Purpose: Skeletal morbidity is common in patients with bone metastases from breast cancer $(\mathrm{BC})$ and can undermine patients' functional independence and quality of life. Previously defined prognostic factors may not reflect current treatment standards and the use of antiresorptive therapies. We report a comprehensive multivariate analysis of potential prognostic factors for skeletal-related events (SREs) using data from a phase III, randomized study of zoledronic acid in patients with bone metastases from BC.

Methods: The trial evaluated the number and timing of SREs (pathologic fracture, palliative radiotherapy to bone, surgery to bone to treat or prevent a fracture, and spinal cord compression) and assessed variables for prognostic significance in univariate and multivariate Cox regression analyses. Continuous variables were categorized with predefined cutpoints. All associations with $P<.05$ were considered significant. A total of 444 zoledronic acid-treated patients with assessments of biochemical markers of bone metabolism and complete baseline variable data were included.

Results: Significant baseline prognostic factors for occurrence of a first SRE by multivariate analyses included age, pain score, prior history of an SRE, predominant lesion type, elevated bone-specific alkaline phosphatase, and lactate dehydrogenase. Prior fracture was found to be prognostic in a reduced multivariate analysis of time to first fracture, but not for time to first palliative radiotherapy.

Conclusions: This model identified several prognostic factors that may be useful in routine clinical care. Validation of these factors in a separate dataset and generation of a prognostic risk score are recommended next steps.

Keywords: Bisphosphonates, breast cancer, bone metastases, risk factor, skeletalrelated event, zoledronic acid 


\section{ABBREVIATIONS}

BAP, bone-specific alkaline phosphatase

$\mathrm{BC}$, breast cancer

BPI, Brief Pain Inventory

$\mathrm{Cl}$, confidence interval

Cr, creatinine

ECOG PS, Eastern Cooperative Oncology Group performance status

$\mathrm{LDH}$, lactate dehydrogenase

NTX, N-telopeptide of type I collagen

$R R$, relative risk

SD, standard deviation

SGOT, serum glutamic oxaloacetic transaminase

SRE, skeletal-related event

ULN, upper limit of normal

ZOL, zoledronic acid 


\section{INTRODUCTION}

Up to $75 \%$ of patients with advanced breast cancer (BC) develop skeletal metastases [1]. Although treatment options at this stage of disease are palliative, median survival is approximately 2 years, with $20 \%$ surviving beyond 5 years [2]. In this context, quality of life and survival are often diminished by the onset of debilitating skeletalrelated events (SREs) including pathologic fracture, bone pain requiring radiotherapy, spinal cord compression, and the requirement for surgery to bone [2]. Moreover, patients may suffer several SREs during their illness, with considerable costs to health services $[3,4]$.

Metastatic bone disease is associated with increased and imbalanced bone turnover, resulting in accelerated bone resorption and, typically, associated increase in bone formation [5]. Bisphosphonates inhibit abnormal bone resorption, thereby reducing the morbidity associated with bone metastases. Thus, bisphosphonates are now standard therapy in patients with bone metastases from BC [6]. Particularly, the large, multicenter, randomized, placebo-controlled trials of zoledronic acid (ZOL) demonstrated reduction in the frequency of SREs versus placebo in BC patients [7], and also in patients with castration-resistant prostate cancer $[8,9]$ and a broad range of other solid tumors, including lung cancer $[10,11]$.

Clinical management of patients with metastatic bone disease from $\mathrm{BC}$ might be improved by identifying easily measurable factors that, either alone or in combination, could be used to predict SREs.

There is considerable interest in the use of bone turnover markers for predicting SRE risk in patients with metastatic bone disease. Disturbances of normal bone metabolism associated with metastatic bone disease may be detected by measuring biochemical markers of bone turnover, including the resorption marker $\mathrm{N}$-telopeptide of 
type I collagen (NTX) and the formation marker bone-specific alkaline phosphatase (BAP). Baseline urine NTX values were correlated with the risk of subsequent SREs [12], and NTX reduction into the normal range was associated with reduced risk of fracture [13]. These findings were subsequently confirmed in much larger data sets [14]. In BC patients who received ZOL, high baseline and on-treatment urine NTX levels correlated with a 2.5-times higher risk of first SRE versus low NTX levels [6]. Subsequent analysis showed that patients with bone metastases from $\mathrm{BC}$ who failed to normalize their urine NTX levels after 3 months of ZOL had a 2-fold increased risk of SREs versus patients who normalized their NTX at 3 months [14].

Other parameters were also implicated as risk factors for SREs in patients with metastatic bone disease from BC, including metastatic disease confined to the skeleton, lesions in long bones, irradiation of lesions (for fracture risk), larger lesion size, and osteolytic radiographic appearance [15]. Prior SRE, number of metastatic bone lesions on diagnostic imaging, and bone pain severity were also implicated as predictive of SREs, although these assessments were made in isolation rather than in multivariate analyses [16]. Exploratory retrospective analysis of data from patients with $\mathrm{BC}$ enrolled in the ZOL trials suggested that patients with a history of SREs were at a significantly higher risk of further SREs than patients with no prior SREs [17].

The phase III, multicenter registration trial of $\mathrm{ZOL}$ in patients with bone metastases from BC demonstrated that a similar proportion of patients receiving $\mathrm{ZOL}$ and pamidronate developed an SRE ( $43 \%$ vs $45 \%$, respectively). Additionally, ZOL significantly reduced the risk of developing an SRE $(H R=0.801 ; P=.037)$ and prolonged time to first SRE (median, 310 vs 174 days, respectively; $P=.013$ ) compared with pamidronate $[18,19]$. Data from this trial provides an extensive database on SREs with associated measurements of clinical and biochemical parameters for each patient. We explored this extensive database to retrospectively investigate a range of possible 
risk factors for SRE in univariate and multivariate analyses. In particular, we focused on risk factors for fracture. 


\section{METHODS}

\section{Patient Population}

Patients in the randomized, double-blinded, multicenter study to evaluate the safety and efficacy of ZOL for bone metastases from BC (or Durie-Salmon stage III multiple myeloma) were enrolled between October 1998 and December 1999 [18,19]. The main efficacy trial endpoint compared the proportion of patients with on-study SREs (defined as pathologic fracture, palliative radiotherapy to bone, surgery to bone to prevent or treat an impending fracture, and spinal cord compression) for ZOL $4 \mathrm{mg}$ versus pamidronate. All patients provided written informed consent, and anticancer treatment could be changed as clinically required throughout the study. Patients were randomized to intravenous infusion of ZOL $4 \mathrm{mg}$, ZOL $8 \mathrm{mg}$, or pamidronate $90 \mathrm{mg}$ administered every 3 to 4 weeks for $\leq 24$ months. During the trial, the $8-\mathrm{mg}$ ZOL dose was reduced to $4 \mathrm{mg}$ based on direction from the renal safety monitoring board; this group was thereafter referred to as the $8 / 4-\mathrm{mg}$ group. All patients had $\geq 1$ radiographically confirmed malignant bone lesions, Eastern Cooperative Oncology Group performance status (ECOG PS) of 0 to 2 , and serum creatinine $<3 \mathrm{mg} / \mathrm{dL}$ (265 $\mu \mathrm{mol} / L)$. No patients had received prior bisphosphonate therapy for their bone lesions. Only patients with BC in the ZOL treatment groups are included in the analyses reported herein.

Trial design and patient evaluation were previously reported $[18,19]$. Radionuclide bone scans and radiographic bone surveys were performed on patients at baseline and then every 3 to 6 months throughout the study. These were reported blindly in a single reporting center. Blood samples were tested for levels of serum BAP and urine samples were tested for levels of NTX. The trial prospectively recorded SRE- 
related data for each patient during the 25-month study, including the occurrence and timing of each of the 4 defined SREs, as well as information on fracture sites.

\section{Statistical Methods}

A panel of variables was selected from available trial data and assessed for baseline prognostic significance in univariate and multivariate Cox-regression analyses. These included age, race, weight, time since bone metastases diagnosis, predominant radiographic appearance of bone lesion(s) (osteolytic/osteoblastic/other), number of bone metastases, pain as assessed by the Brief Pain Inventory (BPI) Composite Pain Score, ECOG PS, history of SRE, history of chemotherapy, concomitant hormone therapy, presence of liver metastases, presence of extraskeletal metastases, and values of NTX, BAP, lymphocyte count, hemoglobin, serum glutamic oxaloacetic acid, albumin, creatinine, and lactate dehydrogenase (LDH). All models were stratified by treatment group (ZOL $4 \mathrm{mg}$ or $8 / 4 \mathrm{mg}$ only); attention was restricted to patients with complete covariate data, including values for NTX, BAP, and creatinine, which were only assessed in North American patients.

Continuous variables were made discrete using predefined cutpoints. Age was categorized into 4 ranges ( $<50, \geq 50$ to $<60, \geq 60$ to $<70$, and $\geq 70$ years old). Weight was categorized into 4 ranges ( $<60, \geq 60$ to $<70, \geq 70$ to $<80$, and $\geq 80 \mathrm{~kg}$ ). The BPI score was also categorized into 4 ranges and scored from 0 to 3 ( 0 for $\mathrm{BPI}$ score $<1.25,1$ for $\mathrm{BPI}$ score $\geq 1.25$ to $<3.00,2$ for BPI score $\geq 3.00$ to $<4.50$, and 3 for BPI score $\geq 4.50$ units). Duration of bone metastases (ie, time from diagnosis of bone metastases) was categorized into 3 ranges: $<3, \geq 3$ to $<12$, and $\geq 12$ months.

For biochemical parameters, 2 approaches were used for defining categorical ranges. First, categories were defined based on quartiles of the study population distribution (4 categories); second, a binary variable was created that indicated whether 
the value was greater than or equal to the upper limit of normal (ULN), with the local ULN used for each center. For LDH, only the latter, dichotomous split was used.

The outcome of primary interest was time to first SRE (ie, time from patient randomization to first on-study SRE); patients not experiencing an SRE were censored at the time of last contact or death. Additional outcomes included time to first pathologic fracture and time to first need for palliative radiotherapy, the 2 most frequent SREs. Because of the competing risk of death, cumulative incidence functions were estimated to plot the proportion of patients experiencing skeletal complications [20,21].

A new vertebral fracture was defined as a decrease in total, anterior, or posterior vertebral height of $\geq 25 \%$ from baseline. During the first year on study, this was determined by the central radiologist by reviewing serial bone surveys performed and any spinal films obtained between the scheduled bone surveys (in the case of symptomatic vertebral compression fracture). Thereafter, the treating physician was responsible for determining SREs related to vertebral fracture.

For all analyses, associations were considered statistically significant if their associated $P$ value was $<.05$. Reduced multivariate models were generated by stepwise backward elimination of the least significant variables in the multivariate model until a reduced model was obtained in which only significant covariates remained. 


\section{RESULTS}

\section{Baseline Demographics and Distribution of First On-Study SREs}

In the phase III trial of ZOL versus pamidronate in patients with bone metastases from $\mathrm{BC}, 742$ and 388 patients were randomized to $\mathrm{ZOL}$ or pamidronate, respectively [19]. Approximately $90 \%$ of patients had $>1$ identifiable site of bone metastasis, and $14.6 \%$ had $\geq 6$ sites of bone involvement. Approximately two thirds of patients had boneonly disease at study entry (Table 1).

Of the 438 patients with an SRE before study entry, 344 ( $80 \%)$ had pathologic fractures, with a mostly balanced distribution between vertebral and non-vertebral sites (Table 2). Radiation for bone pain was required by 248 patients (57\% of those with prior SREs). After study entry, 350 patients (47\% of the 742 patients who received ZOL treatment) experienced $\geq 1$ SRE on study. Data show that 257 patients had $\geq 1$ on-study pathologic fracture, the majority of which were non-vertebral. Additionally, 161 patients required palliative radiotherapy on study. The numbers of on-study events are therefore sufficiently large to permit robust statistical analysis. Of the 742 patients in the ZOL arm, complete baseline assessments for all 21 variables of interest were available for 444 patients. Data from these ZOL-treated patients were included in the univariate and multivariate models described below.

\section{Univariate and Multivariate Analyses of Risk Factors for First On-Study SRE}

Potential risk factors were evaluated for the first on-study SRE. Univariate analyses for first-SRE risk correlations were performed on each of the 21 variables using quartile-based categorical and dichotomous versions of the variables. The following baseline parameters were significantly associated with increased risk of first on-study SRE: increased age, higher number of lesions, higher BPI score, higher ECOG PS, 
history of SRE, predominance of osteolytic lesions, elevated LDH, albumin below normal levels, elevated NTX, and elevated BAP. No other factors showed significant correlations with first SRE risk in univariate analyses.

In full multivariate models, including all 21 baseline covariates, the following were significant factors for first on-study SRE: age $\geq 60$ years, BPI score $>3$ units, history of SRE before study entry, and predominance of osteolytic versus osteoblastic lesions (Table 3). In the reduced multivariate model, each of the significant factors from the multivariate analysis was maintained, and BAP and predominance of osteolytic versus other lesions became significant covariates. Based on this reduced model, risk of a first on-treatment SRE was increased by approximately $70 \%$ among patients older than 60 ; by approximately $60 \%$ in patients who experienced an SRE before starting bisphosphonate therapy; and by approximately 2 -fold in patients with any BPI score $>3$ units, predominantly lytic lesions, or BAP levels $>201.5 \mathrm{U} / \mathrm{L}$ versus the respective comparator groups for each variable. In a separate model based on dichotomous cutpoints, NTX was also found to be a significant covariate for first on-study SRE risk in both univariate and reduced multivariate models (data not shown).

For each of the significant risk factors identified for first on-study SRE in the reduced multivariate model, cumulative incidence function estimates were computed by levels of these factors. These revealed clear separation of the cumulative incidence functions between the covariate categories (Figure 1).

\section{Analyses of Risk Factors for Pathologic Fracture}

Pathologic fractures were the most common SRE subtype and represent a relatively homogenous and objective endpoint. Both the quartile-defined ranges and the dichotomous, value-defined ranges for the biochemical parameters were analyzed. All previous risk factors were tested with the exception of prior pathologic fracture and prior 
radiotherapy to bone, which were separately assessed as covariates (instead of the single composite of "any prior SRE" used in the first SRE risk model).

The analyses based on the full model showed that duration of bone metastases $>12$ months, history of prior pathologic fracture, higher numbers of bone metastases, higher baseline NTX level, predominance of osteolytic lesions, and elevated baseline LDH were significant risk factors for on-study fracture when the biochemical parameters were dichotomized. With the exception of duration of bone metastases, all of these variables remained significant in reduced models. When quartiles were used to categorize the biochemical parameters, broadly similar conclusions were reached, although NTX was no longer significant. Duration of bone metastases remained significant in the reduced model. Prior pathologic fracture was found to be a risk factor for fracture on study $(P<.0001)$, with patients in this group having more than twice the risk of subsequent fracture (Figure 2). Prior radiotherapy to bone was not a significant risk factor for fracture on study.

Analyses were also performed to assess risk factors for vertebral and nonvertebral fractures separately. For both, having bone metastases $>12$ months before initiating bisphosphonate therapy and history of a pathologic fracture were significant risk factors. Number of metastases was also a significant covariate for only non-vertebral fractures, whereas concomitant hormone therapy, predominantly osteolytic lesions, and high baseline NTX levels were also significant covariates for only vertebral fractures. Indeed, for vertebral fractures, patients with NTX levels in the highest quartile range had 7.62-times the risk of fracture versus patients whose NTX levels were in the lowest quartile $(P=.0009$; data not shown). 


\section{Radiation Therapy for Bone Pain and Associated Risk Factors}

The need for palliative radiotherapy to bone was the second most common SRE and is an established surrogate for severe bone pain [22]. Similar to the pathologic fracture analysis, prior SRE was divided between prior fracture and prior palliative radiotherapy, resulting in 22 variables. In the reduced multivariate analyses, only a baseline BPI score of $\geq 3$ units and predominance of osteolytic versus osteoblastic lesions were significantly associated with risk of bone pain requiring radiotherapy (each

approximately 2 - to 3-times the risk; Figure 3). In the quartile-based analyses, the top 2 quartiles of baseline BAP were also significantly associated with an approximately $80 \%$ increased risk versus the lowest BAP quartile (Figure 3; $P=.044$ each). Interestingly, neither prior pathologic fracture nor prior radiation to bone was associated with risk of palliative radiotherapy to bone on study. 


\section{DISCUSSION}

The registration trial comparing ZOL with pamidronate in patients with bone metastases from BC generated an extensive database of demographic characteristics, concomitant therapy, clinical outcomes, and laboratory parameters that is well suited to exploratory analyses. Moreover, all patients in this study received bisphosphonate therapy, which is now the established standard of care for patients with bone metastases from solid tumors [23].

In this analysis, BPI score, ECOG PS, history of SRE, predominance of lytic lesions, and elevated LDH levels were identified as risk factors for developing a first SRE during ZOL therapy. Moreover, the multivariate analyses confirmed the SREprognostic utility of elevated baseline NTX and BAP levels, which has been previously reported in univariate models $[5,6]$. Longer duration of bone disease and history of fractures were also identified as significant risk factors for pathologic fractures. In subanalyses by fracture type, these were the only significant risk factors for nonvertebral fractures, whereas high NTX levels, predominantly osteolytic lesions, and concomitant hormone therapy emerged as additional significant risk factors for vertebral fractures.

For palliative radiotherapy to bone, high baseline BPI score was a risk factor. The relationship between LDH and requirement for radiotherapy was also significant but the inverse of the $\mathrm{LDH}$ and risk relationship for the other SRE endpoints. These risk parameters provide important insight into the development of skeletal morbidity and may identify patients at especially high risk of imminent SREs who might benefit from surgical intervention to prevent an impending fracture or earlier application of radiotherapeutic intervention. 
The risk models evaluated data based on quartile values for the study population and by dichotomous categorization based on established or lab-specific ULNs. Although there were subtle differences between the outcomes of these analyses, they gave broadly similar results. As with all risk factors arising from statistical models, it is worth considering whether there is a rational biologic or behavioral link between the risk factor and the outcome and, conversely, whether there are factors that may have been expected to be significant but were not.

Of the risk factors for an SRE identified in the multivariate analyses, increasing age, elevated NTX, and predominance of osteolytic lesions would all be expected to be associated with weakened mechanical properties of the skeleton. The higher pathologic fracture risk of osteolytic versus other lesion types in $B C$ is consistent with data from patients with metastatic bone disease in prostate cancer, in which lesions are mainly osteoblastic, and radiation to bone is more frequent than pathologic fracture [9]. Because radiation for bone pain is an SRE, BPI score is also a logical risk factor for SREs. History of prior SRE proved to be a significant risk factor and will be discussed further below. It is more difficult to assign a mechanistic explanation to the finding of $\mathrm{LDH}$ as a significant risk factor, although it is noteworthy that LDH has also been implicated as a risk factor in survival analyses from the same trial data and has been linked to disease burden [24]. Indeed, the inverse association observed between palliative radiotherapy risk and elevated LDH could reflect lower use of radiotherapy in patients with a poor prognosis rather than lower bone pain burden in that cohort.

The number of sites of bone metastases did not show significance as risk factors for SRE. For example, patients with $>6$ metastatic sites were no more likely to experience an SRE than patients with 1 metastatic site. This result was somewhat unexpected. 
A clear conclusion from this analysis is that patients with an SRE before starting bisphosphonate therapy have a substantially increased risk of a further SRE on therapy. This emphasizes the value of early bisphosphonate intervention, which is known to reduce or delay SRE occurrence. Moreover, the subanalysis of prior fracture and prior radiation to bone as covariates is especially revealing. Pathologic fracture before initiating bisphosphonate therapy, although not associated with risk of on-treatment radiation to bone, is a strong risk factor for on-treatment pathologic fracture, an observation consistent with postmenopausal osteoporosis-related fractures, in which prior fracture is a recognized risk factor in algorithms for patient management [25]. However, prior radiation to bone is not a predictive factor for future fracture or for future need for radiation to bone, and therefore appears to have a more complicated relationship with subsequent SRE risk. Nonetheless, the need for radiation to bone was associated with BPI score, an expected result that lends added confidence to the analyses.

The purpose of this analysis was to identify clinically useful risk factors for skeletal complications among patients with $\mathrm{BC}$ metastatic to bone who received $\mathrm{ZOL}$. These factors are helpful for quantifying relative risk of events among patients presenting with bone metastases. In some contexts, however, interest may lie in classifying patients into different risk groups. In this case, care must be taken to ensure that these classifications are appropriate, particularly if they are to serve as a basis for treatment recommendations. Validation of the classifications based on statistical models is important before they can be applied clinically. Cross-validation is a common technique useful to assess the agreement between predicted and actual risk groups and is feasible when validation samples are available. The ideal validation sample would also be composed of patients with $\mathrm{BC}$ receiving $\mathrm{ZOL}$ for treating skeletal metastases. At present, there is no such suitable data set. Alternatively, patients from the pamidronate 
arm of the Rosen trial $[18,19,26]$ could be used, but this is less than optimal because risks and risk factors may be different in this group of patients, pamidronate is now used less often, and ZOL produced some significant SRE benefits beyond those produced by pamidronate $[11,19]$. A further challenge in validation of models for risk classification of SREs is the presence of the competing risk for death.

The current study was restricted to analysis of first on-study SRE (ie, first after study enrollment), with all risk factors referring to baseline assessments. Although this is likely to be of most clinical value in terms of patient management after starting bisphosphonates, it may not predict how many total SREs are likely, and the model may become less predictive over time. Updated measurements of some of the predictive factors might overcome this limitation should this be considered necessary in the future. For example, recent reports showed that normalizing NTX levels during treatment is associated with significant reductions in risks of SREs and death versus persistently elevated NTX levels in both the BC and other solid tumors settings [14,27].

Although previous studies analyzed risk factors in isolation, this is the first comprehensive, multivariate investigation of risk factors for SREs in patients with bone metastases from BC. These complications are very common, and physicians need a logical basis on which to determine optimum management of antiresorptive therapy, prophylactic surgery, and frequency of follow-up. Several easily measurable risk factors emerged from this study that could be used to assist patient management, and their combination into a weighted risk score may be possible in the future. On the basis of the present study, this would be a valuable next step; however, as discussed earlier, such factors would require confirmation and validation in a future prospective study before adoption into management guidelines. 


\section{ACKNOWLEDGMENTS}

We are grateful to Cancer Research UK for support for J.E.B. We thank Carol Sledz, PhD, from ProEd Communications, Inc. ${ }^{\circledR}$, for her medical editorial assistance with this manuscript, unrestricted funding for which was provided by Novartis Pharmaceuticals Corporation, East Hanover, New Jersey. 


\section{REFERENCES}

1. Coleman RE (2001) Metastatic bone disease: clinical features, pathophysiology and treatment strategies. Cancer Treat Rev 27:165-176

2. Coleman RE (1997) Skeletal complications of malignancy. Cancer 80(suppl):1588-1594

3. Major PP, Cook RJ, Chen BL et al (2005) Survival-adjusted multiple-event analysis for the evaluation of treatment effects of zoledronic acid in patients with bone metastases from solid tumors. Support Cancer Ther 2:234-240

4. Delea T, McKiernan J, Brandman J et al (2006) Retrospective study of the effect of skeletal complications on total medical care costs in patients with bone metastases of breast cancer seen in typical clinical practice. J Support Oncol 4:341-347

5. Brown JE, Cook RJ, Major P et al (2005) Bone turnover markers as predictors of skeletal complications in prostate cancer, lung cancer, and other solid tumors. $J$ Natl Cancer Inst 97:59-69

6. Coleman RE, Major P, Lipton A et al (2005) Predictive value of bone resorption and formation markers in cancer patients with bone metastases receiving the bisphosphonate zoledronic acid. J Clin Oncol 23:4925-4935

7. Kohno N, Aogi K, Minami H et al (2005) Zoledronic acid significantly reduces skeletal complications compared with placebo in Japanese women with bone metastases from breast cancer: a randomized, placebo-controlled trial. J Clin Oncol 23:3314-3321

8. Saad F, Gleason DM, Murray R et al (2002) A randomized, placebo-controlled trial of zoledronic acid in patients with hormone-refractory metastatic prostate carcinoma. J Natl Cancer Inst 94:1458-1468 
9. Saad F, Gleason DM, Murray R et al (2004) Long-term efficacy of zoledronic acid for the prevention of skeletal complications in patients with metastatic hormonerefractory prostate cancer. J Natl Cancer Inst 96:879-882

10. Rosen LS, Gordon D, Tchekmedyian S et al (2003) Zoledronic acid versus placebo in the treatment of skeletal metastases in patients with lung cancer and other solid tumors: a phase III, double-blind, randomized trial—the Zoledronic Acid Lung Cancer and Other Solid Tumors Study Group. J Clin Oncol 21:31503157

11. Rosen LS, Gordon D, Tchekmedyian NS et al (2004) Long-term efficacy and safety of zoledronic acid in the treatment of skeletal metastases in patients with nonsmall cell lung carcinoma and other solid tumors: a randomized, Phase III, double-blind, placebo-controlled trial. Cancer 100:2613-2621

12. Brown JE, Thomson CS, Ellis SP et al (2003) Bone resorption predicts for skeletal complications in metastatic bone disease. Br J Cancer 89:2031-2037

13. Lipton A, Demers L, Curley E et al (1998) Markers of bone resorption in patients treated with pamidronate. Eur J Cancer 34:2021-2026

14. Lipton A, Cook R, Saad F et al (2008) Normalization of bone markers is associated with improved survival in patients with bone metastases from solid tumors and elevated bone resorption receiving zoledronic acid. Cancer 113:193201

15. Patel B, DeGroot H, 3rd (2001) Evaluation of the risk of pathologic fractures secondary to metastatic bone disease. Orthopedics 24:612-617; quiz 618-619

16. Major PP, Cook RJ, Lipton A et al (2009) Natural history of malignant bone disease in breast cancer and the use of cumulative mean functions to measure skeletal morbidity. BMC Cancer 9:272 
17. Kaminski M, Rosen LS, Gordon D et al Zoledronic acid is superior to pamidronate in patients with breast cancer and multiple myeloma who are at high risk for skeletal complications [poster]. Presented at: Primary Therapy of Early Breast Cancer 9th International Conference; 26 - 29 January, 2005; St. Gallen, Switzerland. Abstract 107.

18. Rosen LS, Gordon D, Kaminski M et al (2001) Zoledronic acid versus pamidronate in the treatment of skeletal metastases in patients with breast cancer or osteolytic lesions of multiple myeloma: a phase III, double-blind, comparative trial. Cancer J 7:377-387

19. Rosen LS, Gordon DH, Dugan W, Jr. et al (2004) Zoledronic acid is superior to pamidronate for the treatment of bone metastases in breast carcinoma patients with at least one osteolytic lesion. Cancer 100:36-43

20. Kalbfleisch JD, Prentice RL (2002) The Statistical Analysis of Failure Time Data. John Wiley \& Sons, New York, NY

21. Lawless JF (2003) Statistical Models and Methods for Lifetime Data. John Wiley \& Sons, Hoboken, NJ

22. Barton MB, Dawson R, Jacob $S$ et al (2001) Palliative radiotherapy of bone metastases: an evaluation of outcome measures. J Eval Clin Pract 7:47-64

23. Hillner BE, Ingle JN, Chlebowski RT et al (2003) American Society of Clinical Oncology 2003 update on the role of bisphosphonates and bone health issues in women with breast cancer. J Clin Oncol 21:4042-4057

24. Coleman RE, Brown J, Cook R (2008) Identification of serum lactate dehydrogenase (LDH) as a significant prognostic variable for survival: multivariate analysis in women with metastatic breast cancer (BC). Cancer Treat Rev 34(suppl 1):28-29. Abstract P61 
25. Jackson RD, Donepudi S, Mysiw WJ (2008) Epidemiology of fracture risk in the Women's Health Initiative. Curr Osteoporos Rep 6:155-161

26. Rosen LS, Gordon D, Kaminski M et al (2003) Long-term efficacy and safety of zoledronic acid compared with pamidronate disodium in the treatment of skeletal complications in patients with advanced multiple myeloma or breast carcinoma: a randomized, double-blind, multicenter, comparative trial. Cancer 98:1735-1744

27. Lipton A, Cook RJ, Major P et al (2007) Zoledronic acid and survival in breast cancer patients with bone metastases and elevated markers of osteoclast activity. Oncologist 12:1035-1043 


\section{TABLES}

Table 1. Patient Demographics and Biochemistry at Baseline

\begin{tabular}{|c|c|c|c|}
\hline Variable & Patients, n (\%) & Mean (SD) & Range \\
\hline $\begin{array}{l}\text { Age, years } \\
\quad 0 \text { to }<50 \\
\quad \geq 50 \text { to }<60 \\
\quad \geq 60 \text { to }<70 \\
\geq 70\end{array}$ & $\begin{array}{c}\mathrm{N}=742 \\
207(27.9) \\
213(28.7) \\
181(24.4) \\
141(19.0)\end{array}$ & $57.8(12.4)$ & 24 to 95 \\
\hline $\begin{array}{l}\text { Weight, } \mathrm{kg} \\
\qquad \begin{array}{l}0 \text { to }<60 \\
\geq 60 \text { to }<70 \\
\geq 70 \text { to }<80 \\
\geq 80\end{array}\end{array}$ & $\begin{array}{l}\mathrm{N}=710 \\
145(20.4) \\
222(31.3) \\
163(23.0) \\
180(25.4)\end{array}$ & $71.7(15.7)$ & 34.5 to 171.5 \\
\hline $\begin{array}{l}\text { BPI Composite Pain Score, units } \\
\quad<1.25 \\
\geq 1.25 \text { to }<3.00 \\
\geq 3.00<4.50 \\
\geq 4.50\end{array}$ & $\begin{array}{l}N=682 \\
162(23.8) \\
176(25.8) \\
153(22.4) \\
191(28.0)\end{array}$ & $3.035(2.232)$ & 0 to 10.0 \\
\hline $\begin{array}{l}\text { Duration of cancer at study entry, years } \\
\qquad \leq 5 \\
\quad \geq 5\end{array}$ & $\begin{array}{l}N=742 \\
375(50.5) \\
367(49.5)\end{array}$ & $6.5(5.9)$ & 0.024 to 32.4 \\
\hline $\begin{array}{l}\text { Duration of bone metastases, months } \\
\qquad \begin{array}{l}0 \text { to }<3 \\
\geq 3 \text { to }<12 \\
\geq 12\end{array}\end{array}$ & $\begin{array}{l}\mathrm{N}=738 \\
331(44.9) \\
167(22.6) \\
240(32.5)\end{array}$ & $15.7(29.0)$ & 0.143 to 318 \\
\hline $\begin{array}{l}\text { NTX, nmol/mmol creatinine } \\
\quad<64 \\
\quad \geq 64\end{array}$ & $\begin{array}{l}N=490 \\
197(40.2) \\
293(59.8)\end{array}$ & $133.7(474.1)$ & 8 to 10193 \\
\hline $\begin{array}{r}\mathrm{BAP}, \mathrm{U} / \mathrm{L} \\
\quad<146 \\
\geq 146\end{array}$ & $\begin{array}{c}N=501 \\
130(25.9) \\
371(74.1)\end{array}$ & $268(228.5)$ & 41 to 2043 \\
\hline $\begin{array}{l}\text { Lymphocytes, \% } \\
\quad<\text { ULN } \\
\quad \geq \text { ULN }\end{array}$ & $\begin{array}{l}N=727 \\
669(92.0) \\
58(8.0)\end{array}$ & $25.1(12.5)$ & 2.2 to 88 \\
\hline $\begin{array}{l}\text { Hemoglobin, } \mathrm{g} / \mathrm{dL} \\
\quad \leq 12 \\
\quad>12\end{array}$ & $\begin{array}{c}N=729 \\
364(49.9) \\
365(50.1)\end{array}$ & $12.0(1.5)$ & 4.6 to 16.4 \\
\hline $\begin{array}{l}\text { SGOT, U/L } \\
\quad<\text { ULN } \\
\quad \geq \text { ULN }\end{array}$ & $\begin{array}{l}\mathrm{N}=735 \\
446(60.7) \\
289(39.3)\end{array}$ & $35.9(31.9)$ & 7 to 476 \\
\hline $\begin{array}{l}\text { Albumin, } g / L \\
\quad \leq 35 \\
\quad>35\end{array}$ & $\begin{array}{c}\mathrm{N}=735 \\
94(12.8) \\
641(87.2)\end{array}$ & $40.0(4.2)$ & 26 to 54 \\
\hline
\end{tabular}




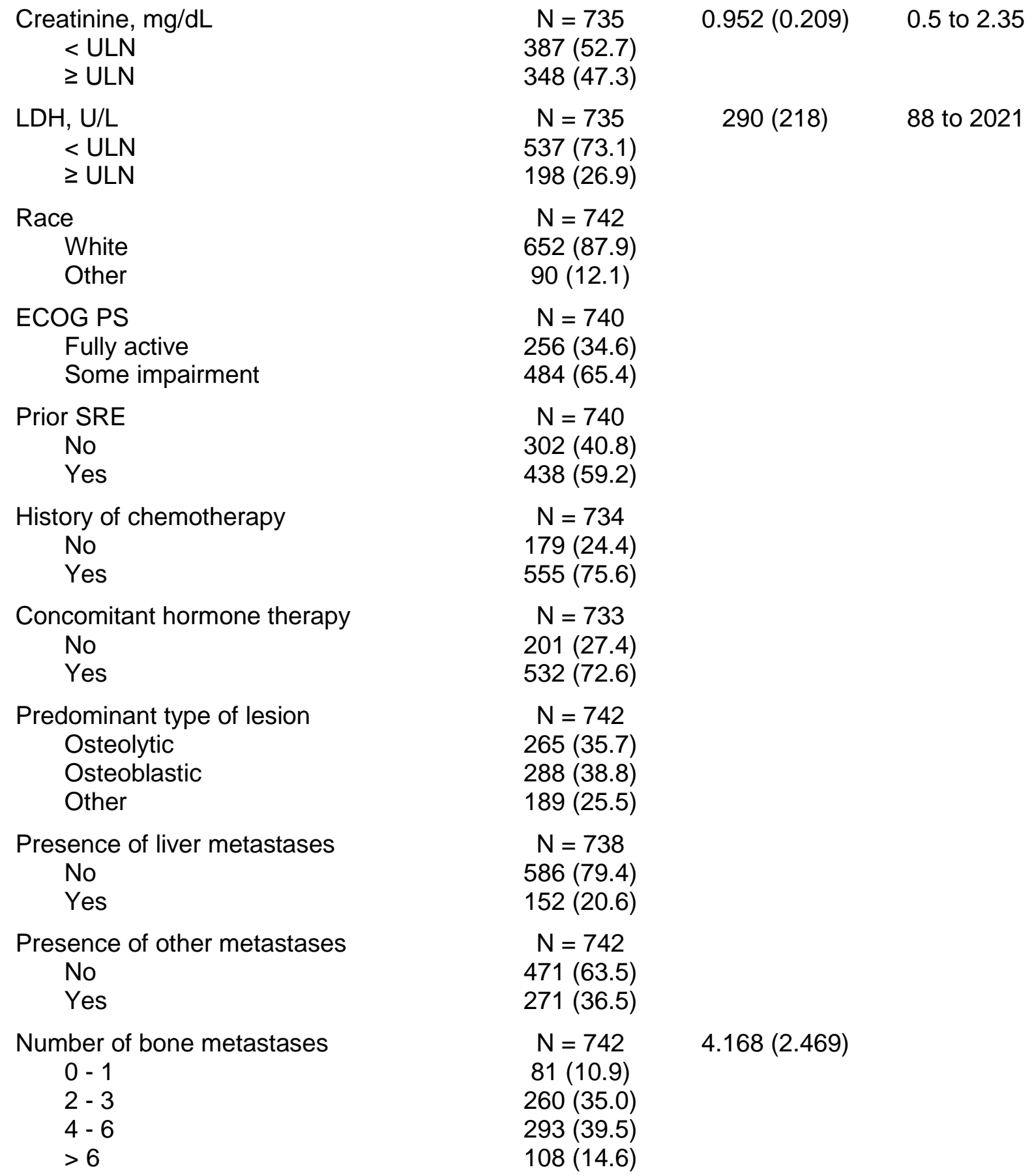

Abbreviations: BAP, bone-specific alkaline phosphatase; BPI, Brief Pain Inventory; ECOG PS, Eastern Cooperative Oncology Group performance status; LDH, lactate dehydrogenase; NTX, N-telopeptide of type I collagen; SD, standard deviation; SGOT, serum glutamic oxaloacetic transaminase, SRE, skeletal-related event; ULN, upper limit of normal. 
Table 2. Distribution of SREs in Terms of SRE Before Study Entry and in Terms of First On-Study SRE

\begin{tabular}{lcc}
\hline Type of SRE & Before study entry, $\mathbf{n}^{\mathbf{a}}(\%)^{\mathbf{b}}$ & On study, $\mathbf{n}^{\mathbf{a}}(\%)^{\mathbf{b}}$ \\
\hline Total SRE & $438(59.0)$ & $350(47.2)$ \\
$\geq 1$ Pathologic fracture & $344(46.4)$ & $257(34.6)$ \\
Non-vertebral fracture & $215(29.0)$ & $193(26.0)$ \\
Vertebral fracture & $225(30.3)$ & $123(16.6)$ \\
Radiation to bone & $248(33.4)$ & $161(21.7)$ \\
\hline
\end{tabular}

Abbreviation: SRE, skeletal-related event.

${ }^{a}$ Number of patients with at least 1 event.

${ }^{b}$ Percentages are based on the entire population $(\mathrm{N}=742)$. 
Table 3. Multivariate Analysis of Predictive Factors for Occurrence of First SRE

\begin{tabular}{|c|c|c|c|c|c|c|}
\hline \multirow[b]{2}{*}{ Variable } & \multicolumn{3}{|c|}{ Full model } & \multicolumn{3}{|c|}{ Reduced model } \\
\hline & RR & $95 \% \mathrm{Cl}$ & $P$ value & $\mathbf{R R}$ & $95 \% \mathrm{Cl}$ & $P$ value \\
\hline $\begin{array}{l}\text { Bone mets duration }<3 \text { months } \\
\quad \geq 3 \text { to }<12 \text { months } \\
\quad \geq 12 \text { months }\end{array}$ & $\begin{array}{l}0.686 \\
0.735\end{array}$ & $\begin{array}{l}0.455,1.035 \\
0.517,1.045\end{array}$ & $\begin{array}{l}.0723 \\
.0869\end{array}$ & & & \\
\hline $\begin{aligned} & \text { Age }<50 \text { years } \\
& \geq 50 \text { to }<60 \text { years } \\
& \geq 60 \text { to }<70 \text { years } \\
& \geq 70 \text { years }\end{aligned}$ & $\begin{array}{l}0.962 \\
1.820 \\
1.616\end{array}$ & $\begin{array}{l}0.630,1.469 \\
1.181,2.803 \\
1.009,2.588\end{array}$ & $\begin{array}{l}.8572 \\
.0066 \\
.0459\end{array}$ & $\begin{array}{l}0.868 \\
1.681 \\
1.597\end{array}$ & $\begin{array}{l}0.588,1.281 \\
1.146,2.467 \\
1.069,2.385\end{array}$ & $\begin{array}{l}.4755 \\
.0079 \\
.0221\end{array}$ \\
\hline $\begin{array}{l}\text { Weight }<60 \mathrm{~kg} \\
\quad \geq 60 \text { to }<70 \mathrm{~kg} \\
\quad \geq 70 \text { to }<80 \mathrm{~kg} \\
\geq 80 \mathrm{~kg}\end{array}$ & $\begin{array}{l}1.045 \\
0.949 \\
1.228\end{array}$ & $\begin{array}{l}0.680,1.605 \\
0.598,1.506 \\
0.805,1.873\end{array}$ & $\begin{array}{l}.8408 \\
.8244 \\
.3409\end{array}$ & & & \\
\hline $\begin{array}{l}\text { BPI Composite Pain Score }<1.25 \\
\quad \geq 1.25 \text { to }<3.00 \text { units } \\
\geq 3.00 \text { to }<4.50 \text { units } \\
\geq 4.50 \text { units }\end{array}$ & $\begin{array}{l}1.129 \\
1.696 \\
1.981\end{array}$ & $\begin{array}{l}0.717,1.777 \\
1.062,2.709 \\
1.231,3.188\end{array}$ & $\begin{array}{l}.6003 \\
.0269 \\
.0049\end{array}$ & $\begin{array}{l}1.230 \\
1.915 \\
2.047\end{array}$ & $\begin{array}{l}0.797,1.900 \\
1.247,2.941 \\
1.336,3.136\end{array}$ & $\begin{array}{l}.3492 \\
.0030 \\
.0010\end{array}$ \\
\hline $\begin{array}{l}\text { ECOG PS: Fully active } \\
\text { ECOG PS: Some impairment }\end{array}$ & 1.160 & $0.822,1.637$ & .3990 & & & \\
\hline $\begin{array}{l}\text { Race: White } \\
\text { Race: Black/Asian/Other }\end{array}$ & 0.918 & $0.589,1.431$ & .7056 & & & \\
\hline Prior SRE & 1.697 & $1.206,2.387$ & .0024 & 1.632 & $1.198,2.224$ & .0019 \\
\hline History of chemotherapy & 1.152 & $0.774,1.715$ & .4845 & & & \\
\hline Concomitant hormone therapy & 0.993 & $0.704,1.399$ & .9663 & & & \\
\hline $\begin{array}{l}\text { Liver metastases } \\
\text { Lung/Brain/Other metastases }\end{array}$ & $\begin{array}{l}0.757 \\
1.002\end{array}$ & $\begin{array}{l}0.509,1.126 \\
0.741,1.356\end{array}$ & $\begin{array}{l}.1694 \\
.9879\end{array}$ & & & \\
\hline
\end{tabular}


Number of metastases: 0 to 1

Number of metastases: 2 to 3

Number of metastases: 4 to 6

Number of metastases: $>6$

$\begin{array}{lll}0.669 & 0.380,1.179 & .1647 \\ 1.102 & 0.635,1.911 & .7295 \\ 0.821 & 0.437,1.542 & .5397\end{array}$

Predominant lesion: osteolytic

Predominant lesion: osteoblastic

$0.605 \quad 0.424,0.865 \quad .0059$

0.837

.0059

0.564

$0.410,0.775$

.0004

Predominant lesion: other

1.159

$0.734,1.829$

.5277

$\geq 47.0$ to $<76.0 \mathrm{nmol} / \mathrm{mmol}$ creatinine

1.427

$0.883,2.307$

1468

$\geq 132 \mathrm{nmol} / \mathrm{mmol}$ creatinine

$0.787,2.388$

.2648

$\mathrm{BAP}<141.25 \mathrm{U} / \mathrm{L}$

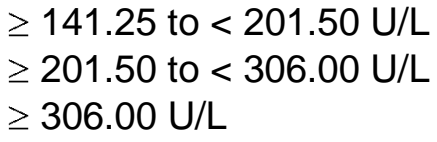

$0.704,1.753$

.6516

$0.952,2.400$

1.512

$0.873,2.537$

.0800

.1441

1.303

1.767

$0.856,1.983$

.2168

1.488

$0.444,1.547$

.5547

Hemoglobin $<10.9 \mathrm{~g} / \mathrm{dL}$ $\geq 10.9$ to $<12.0 \mathrm{~g} / \mathrm{dL}$

$\geq 12.0$ to $<13.0 \mathrm{~g} / \mathrm{dL}$

$0.705,1.682$

.6999

1.089

$0.782,1.916$

.3763

$\geq 13.0 \mathrm{~g} / \mathrm{dL}$

$0.505,1.361$

.4596

SGOT $<21.0 \mathrm{U} / \mathrm{L}$

$\geq 21.0$ to $<27.0 \mathrm{U} / \mathrm{L}$

$\geq 27.0$ to $<39.0 \mathrm{U} / \mathrm{L}$

$\geq 39.0 \mathrm{U} / \mathrm{L}$

0.878

$0.553,1.396$

.5826

0.779

$0.501,1.210$

.2657

0.981

$0.582,1.652$

.9410

Albumin $<37.0 \mathrm{~g} / \mathrm{L}$

$$
\begin{aligned}
& \geq 37.0 \text { to }<40.1 \mathrm{~g} / \mathrm{L} \\
& \geq 40.1 \text { to }<43.0 \mathrm{~g} / \mathrm{L} \\
& \geq 43.0 \mathrm{~g} / \mathrm{L}
\end{aligned}
$$

$0.625,1.564$

.9620

0.654

$0.379,1.128$

.1267

0.951

$0.555,1.630$

.8549 


\begin{tabular}{|c|c|c|c|c|c|c|}
\hline $\begin{array}{l}\text { Creatinine }<0.800 \mathrm{mg} / \mathrm{dL} \\
\quad \geq 0.800 \text { to }<0.900 \mathrm{mg} / \mathrm{dL} \\
\quad \geq 0.900 \text { to }<1.007 \mathrm{mg} / \mathrm{dL} \\
\quad \geq 1.007 \mathrm{mg} / \mathrm{dL}\end{array}$ & $\begin{array}{l}0.851 \\
0.754 \\
0.942\end{array}$ & $\begin{array}{l}0.493,1.467 \\
0.460,1.234 \\
0.538,1.649\end{array}$ & $\begin{array}{l}.5609 \\
.2611 \\
.8341\end{array}$ & & & \\
\hline $\mathrm{LDH} \geq \mathrm{ULN}$ & 1.496 & $0.995,2.251$ & .0530 & 1.492 & $1.063,2.096$ & .0209 \\
\hline
\end{tabular}

Abbreviations: BAP, bone-specific alkaline phosphatase; BPI, Brief Pain Inventory; Cl, confidence interval; EGOG PS, Eastern Cooperative Oncology Group performance status; LDH, lactate dehydrogenase; NTX, N-telopeptide of type I collagen; RR, relative risk; SGOT, serum glutamic oxaloacetic transaminase; SRE, skeletal-related event; ULN, upper limit of normal.

${ }^{a}$ The models were limited to patients with complete baseline assessments for all the variables listed $(n=435)$. 


\section{FIGURE LEGENDS}

Figure 1. The proportion of patients with at least 1 skeletal-related event as a function of time on study up to 24 months. Each of the 7 parameters showing statistical significance in the multivariate models is included: (A) age, (B) Brief Pain Inventory (BPI) Composite Pain Score, (C) SRE history, (D) predominant lesion, (E) N-telopeptide of type I collagen (NTX), (F) bonespecific alkaline phosphatase (BAP; quartiles as cutpoints), and (G) lactate dehydrogenase (LDH). Abbreviations: $\mathrm{Cl}$, confidence interval; $\mathrm{Cr}$, creatinine; RR, relative risk; SRE, skeletalrelated event; ULN, upper limit of normal.

Figure 2. Results of multivariate analysis of parameters that showed significance for first pathologic fracture. Estimates for the full and reduced models are shown using $(A)$ dichotomized model and (B) quartile-defined range. Although not significant, other variables investigated included age, weight, Brief Pain Inventory Composite Pain Score, Eastern Cooperative Oncology Group performance status, race, prior pathologic fracture, history of chemotherapy, concomitant hormone therapy, liver metastases (mets), lung/brain/other mets, number of mets, bone-specific alkaline phosphatase, lymphocytes, hemoglobin, serum glutamic oxaloacetic transaminase, albumin, and creatinine. Abbreviations: $\mathrm{Cl}$, confidence interval; $\mathrm{Cr}$, creatinine; LDH, lactate dehydrogenase; NTX, N-telopeptide of type I collagen; RR, relative risk; ULN, upper limit of normal. 
Figure 3. Results of multivariate analysis of parameters that showed significance for first radiation to bone. Estimates for full and reduced models are shown using $(A)$ dichotomized model and (B) quartile-defined range. Although not significant, other variables investigated included duration of bone metastases, age, weight, Eastern Cooperative Oncology Group performance status, race, prior pathologic fracture, prior radiation to bone, history of chemotherapy, concomitant hormone therapy, liver metastases, lung/brain/other metastases, number of metastases, N-telopeptide of type I collagen levels, lymphocytes, hemoglobin, serum glutamic oxaloacetic transaminase, albumin, creatinine, and lactate dehydrogenase. Abbreviations: BAP, bone-specific alkaline phosphatase; BPI, Brief Pain Inventory; Cl, confidence interval; $R R$, relative risk. 
Figure 1

A

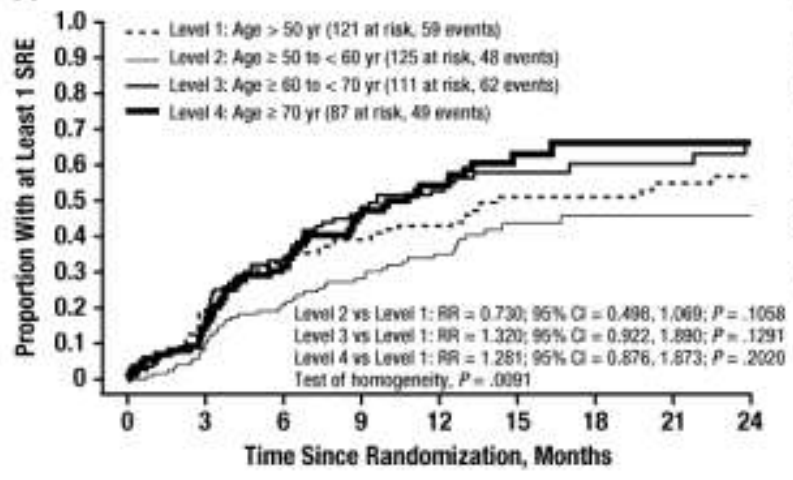

C

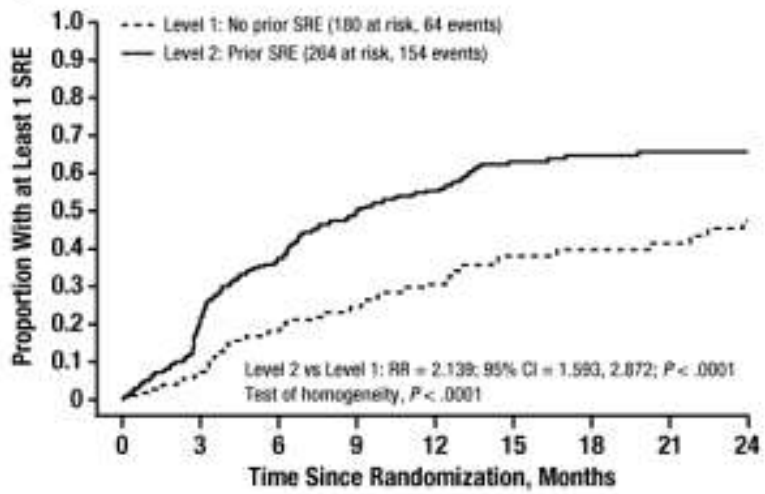

E

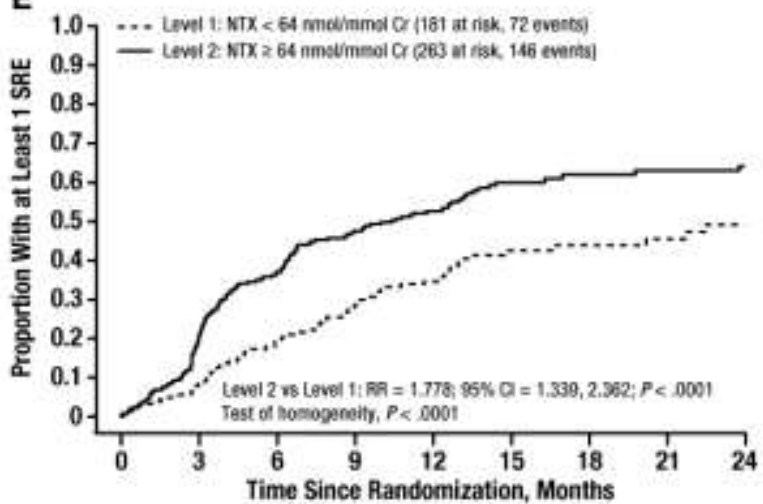

G

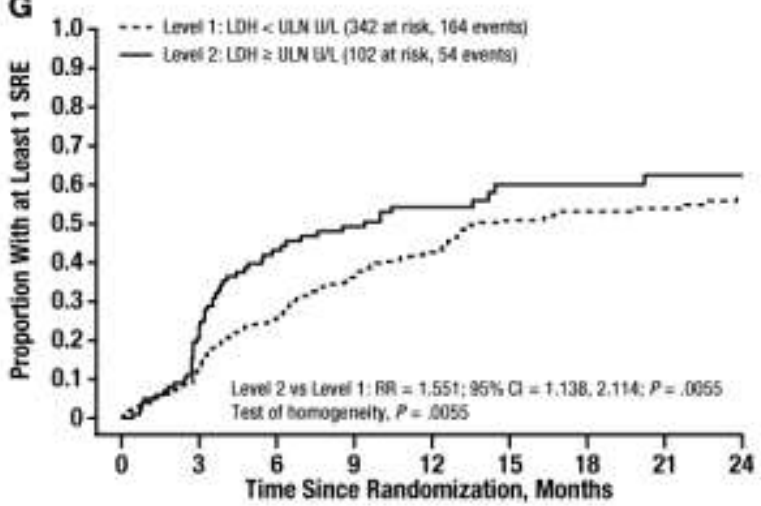

B

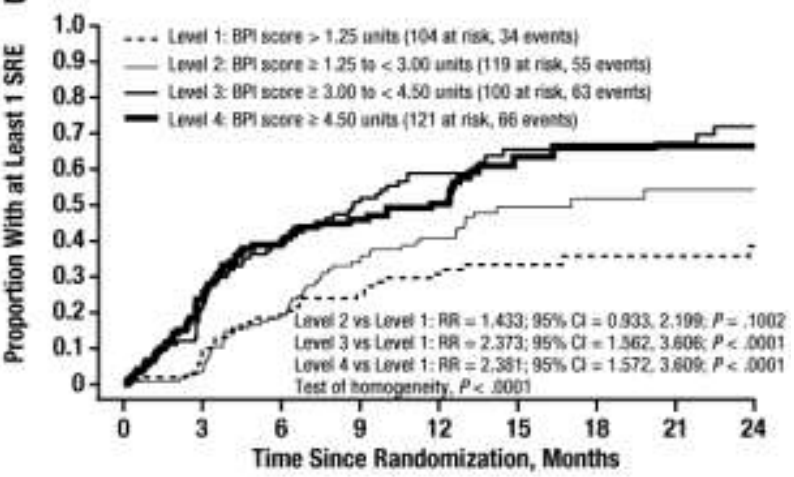

D

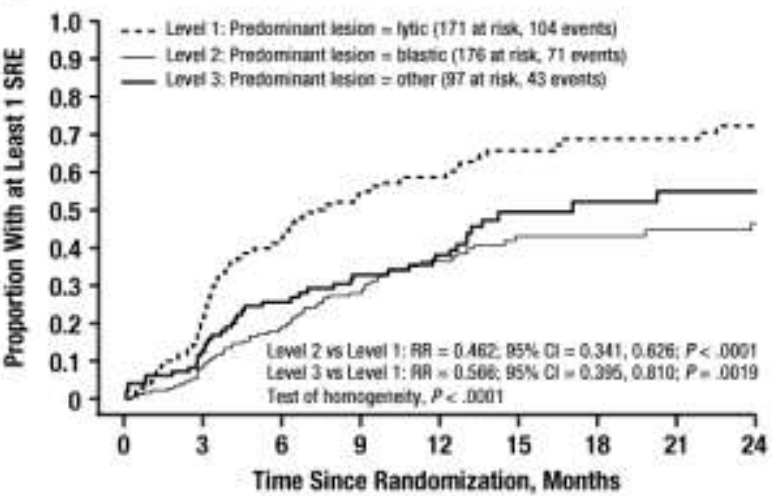

F $1.0 \ldots$ Level 1: BWP $<141.25$ uL (113 at risk, 40 ements)

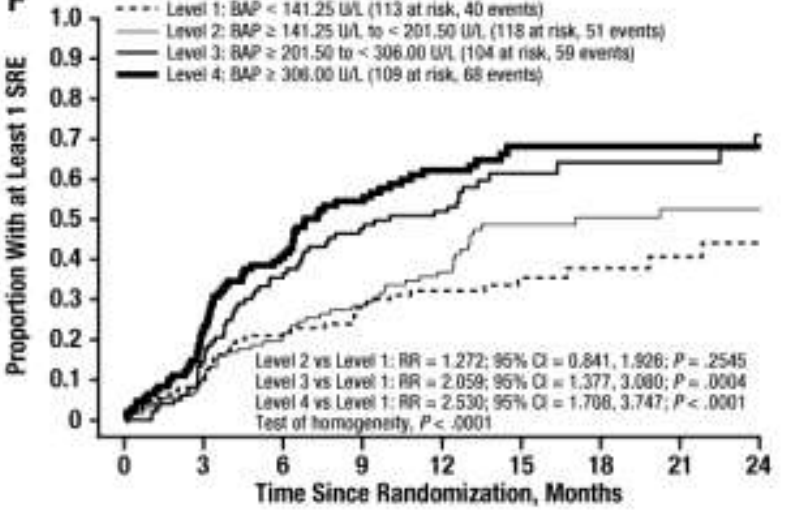


Figure 2

A Dichotomized biochemical parameters

Bone mets duration $\geq 3$ mo to $<12$ mo

Bone mets duration $\geq 12 \mathrm{mo}$

Prior pathologic fracture

Predominant lesion: blastic

Predominant lesion: other

NTX $\geq 64 \mathrm{nmol} / \mathrm{mmol}$

LDH $\geq$ ULN U/L

B Quartile-based biochemical parameters

Bone mets duration $\geq 3$ to $<12$ mo

Bone mets duration $\geq 12 \mathrm{mo}$

Prior pathologic fracture

Predominant lesion: blastic

Predominant lesion: other

NTX $\geq 47.0$ to $<76.0 \mathrm{nmol} / \mathrm{mmol} \mathrm{Cr}$ NTX $\geq 76.0$ to $<132.0 \mathrm{nmol} / \mathrm{mmol} \mathrm{Cr}$

NTX $\geq 132.0 \mathrm{nmol} / \mathrm{mmol} \mathrm{Cr}$

$\mathrm{LDH} \geq U L \mathrm{~N}$ U/L

Full model .....- Reduced model

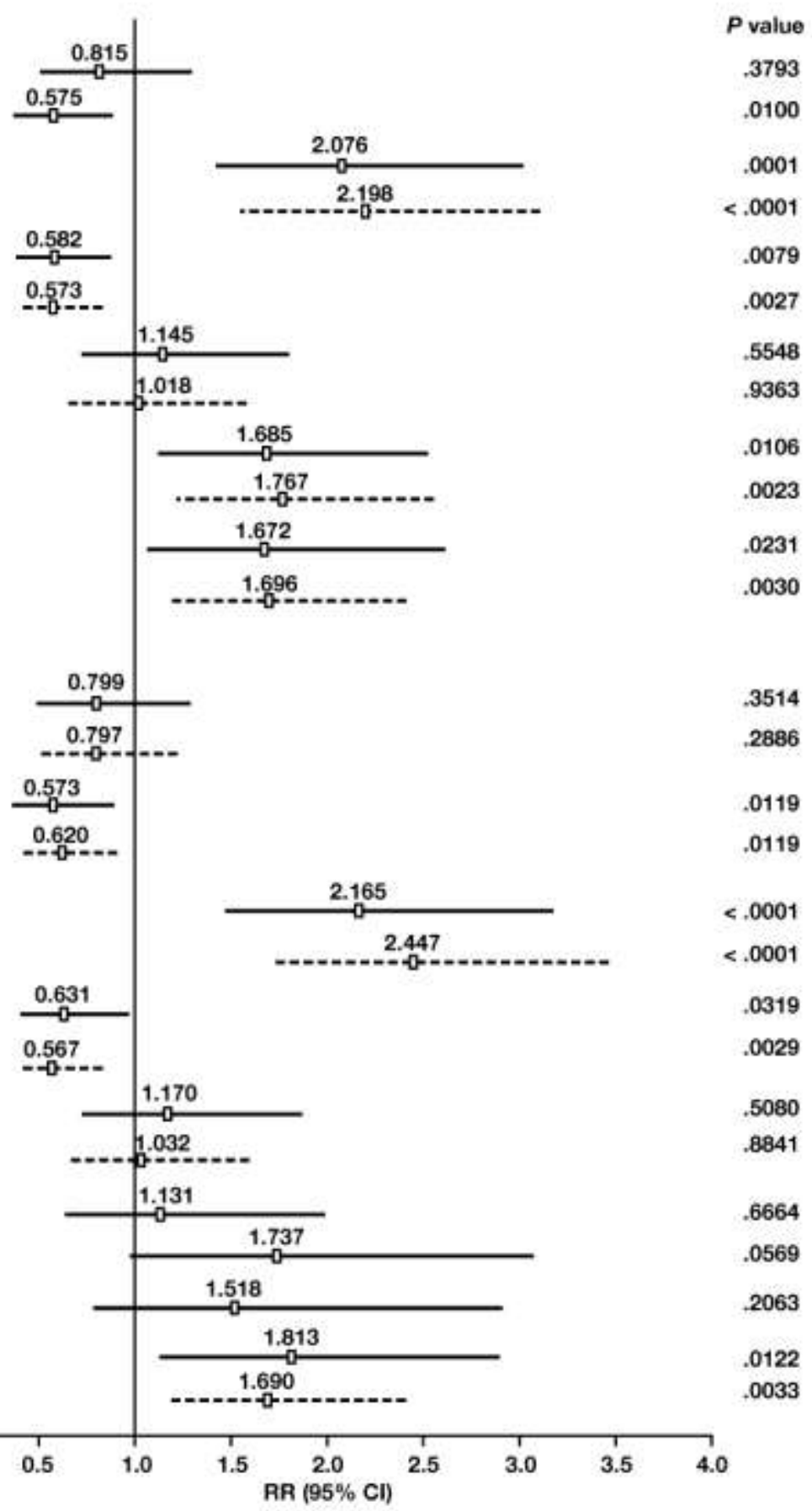

value

0100

0001

0027

5548

9363

0106

0023

0231

0030

3514

2886

0119

0119

.0001

.0001

0029

5080

8841

6664

0569

2063

0122

0033 
Figure 3

A Dichotomized biochemical parameters

$\mathrm{BPI}$ score $\geq 1.25$ to $<3.00$ units

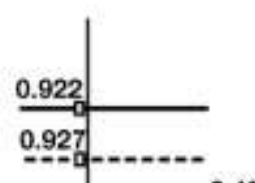

$P$ value

BPI score $\geq 3.00$ to $<4.50$ units

(1)

BPI score $\geq 4.50$ units

Predominant lesion: blastic

Predoninant 0.44

B Quartile-based

biochemical parameters

BPI score $\geq 1.25$ to $<3.00$ units

BPI score $\geq 3.00$ to $<4.50$ units

$\mathrm{BPI}$ score $\geq 4.50$ units

\begin{tabular}{l} 
Predominant lesion: blastic \\
Predominant lesion: other \\
BAP $\geq 141.25$ to $<201.50 \mathrm{U} / \mathrm{L}$ \\
BAP $\geq 201.50$ to $<306.00 \mathrm{U} / \mathrm{L}$ \\
BAP $\geq 306.00 \mathrm{U} / \mathrm{L}$ \\
\hline-- Full model
\end{tabular}

\begin{tabular}{lllllll|lll|}
\hline 0 & 1 & 2 & 3 & 4 & 5 & 6 & 7 & 8 & 9 \\
& & RR $(95 \% \mathrm{Cl})$ & & &
\end{tabular}

